\title{
POLÍTICAS CURRICULARES DE EDUCAÇÃO INFANTIL: UM OLHAR PARA AS INTERFACES ENTRE GÊNERO, SEXUALIDADE E ESCOLA
}

\author{
Rodrigo Saballa de Carvalho* \\ Bianca Salazar Guizzo**
}

\section{RESUMO}

Experiências que se vinculam a gênero e sexualidade são vivenciadas por crianças pequenas quando sobre elas já são constituídas expectativas com relação às suas identidades sexuais e de gênero. A partir das contribuições dos Estudos Culturais e dos Estudos de Gênero, de viés pós-estruturalista, o presente artigo tem como principais objetivos: 1) problematizar a forma como as questões de gênero e sexualidade são colocadas em políticas curriculares propostas para a Educação Infantil; 2) discutir o modo como professoras percebem o trabalho com essas questões na escola. Os resultados mostraram que, de algumas décadas para cá, tem havido a inserção das temáticas de gênero e sexualidade em políticas públicas e curriculares, mas ainda de modo incipiente. Além disso, apontaram para a necessidade de haver um maior investimento na formação de quem atua na Educação Infantil para que efetivamente haja a promoção de práticas educativas não discriminatórias.

Palavras-chave: Gênero. Sexualidade. Currículo. Educação Infantil.

\begin{abstract}
CURRICULUM POLICIES FOR EARLY CHILDHOOD EDUCATION: A GAZE ON GENDER, SEXUALITY AND SCHOLL

Experiences that are linked to gender and sexuality are experienced by young children when expectations about their sexual and gender identities are established. From the contributions of two different fields, Cultural Studies and Gender Studies, with post-structuralism approach, this paper aims: 1) to discuss how issues of gender and sexuality are placed in curricular policy proposals for Early Childhood Education; 2) to discuss how teachers perceive the work with these issues in schools. The results showed that over the past few decades, themes of gender and sexuality has been included in some public and curriculum policies, but it is not enough yet. Furthermore, it showed the need for greater investment in the formation of those engaged in Early Childhood Education for the promotion of non-discriminatory educational practices.
\end{abstract}

Keywords: Gender. Sexuality. Curriculum. Early Childhood Education.

* Doutor em Educação pela Universidade Federal do Rio Grande do Sul (UFRGS). Pós-doutor em Educação pela Universidade Federal de Pelotas (UFPEL). Professor do Curso de Licenciatura em Pedagogia da Universidade Federal da Fronteira Sul (UFFS).rsaballa@terra.com.br

** Doutora em Educação pela Universidade Federal do Rio Grande do Sul (UFRGS). Professora nos cursos de licenciatura e no Programa de Pós-Graduação em Educação da Universidade Luterana do Brasil (ULBRA). Integrante do Grupo de Estudos de Educação e Relações de Gênero (GEERGE/ULBRA). bguizzo_1@hotmail.com 


\section{RESUMEN}

\section{POLÍTICAS CURRICULARES DE EDUCACIÓN INFANTIL: UNA MIRADA SOBRE LA RELACIÓN ENTRE GÉNERO, SEXUALIDAD Y ESCUELA}

Experiencias que se vinculan con género y sexualidad son vividas por los niños cuando ya se establecen expectativas con respecto a su identidad sexual y de género. A partir de las contribuciones de los Estudios Culturales y Estudios de Género, especialmente los que se vinculan a vertiente post-estructuralista, este artículo tiene como sus principales objetivos: 1) problematizar cómo se colocan las cuestiones de género y sexualidad en las propuestas de política curricular para la Educación Infantil; 2) discutir cómo los profesores perciben el trabajo con estos temas en la escuela. Los resultados mostraron que hace algunas décadas, se ha producido la incorporación de las cuestiones de género y sexualidad en las políticas públicas y curriculares, pero aún de manera incipiente. Además, los resultados señalaron la necesidad de mayor inversión en formación de quien actúa en la Educación Infantil para que efectivamente exista la promoción de prácticas educativas no discriminatorias.

Palabras claves: Género. Sexualidad. Currículo. Educación Infantil.

\section{Para um início de discussão...}

“[...] é precisamente onde os problemas são mais intratáveis e menos passíveis de resolução que a política mais importa" (SCOTT, 2005, p. 29).

Gênero e sexualidade nos discursos das políticas curriculares de Educação Infantil é o nosso foco de análise no presente artigo. A escolha pela análise das proposições curriculares da primeira etapa da Educação Básica em suas interfaces com a formação docente justifica-se pelo fato de as relações estabelecidas pelas crianças com seus pares na Educação Infantil serem um importante modo de iniciação na vida social mais ampla. Conforme Finco (2010, p. 52), a primeira infância é um "período em que as crianças passam a conhecer e aprender sistemas de regras e valores, interagindo e participando de construções sociais". Por essa razão, é importante que seja analisado o papel da educação na socialização das crianças realizada na Educação Infantil a partir do questionamento dos processos de diferenciação entre meninos e meninas e da promoção de uma prática educativa não discriminatória.

Corroborando os argumentos apresentados, Vianna e Unbehaum (2004) afirmam que a compreensão das relações de gênero pela escola corre o risco de permanecer em segundo plano, uma vez que poucas vezes as políticas as mencionam, e quando o fazem, não exploram em todos os temas curriculares os antagonismos de gênero presentes na organização do ensino e no cotidiano escolar.

De qualquer modo é importante pontuar que de algumas décadas para cá tem havido a inclusão das temáticas de gênero e sexualidade em documentos vinculados à área da educação, mas elas ainda não são suficientes. Atualmente defende-se que uma das finalidades fundamentais nos âmbitos escolares deve ser preparar crianças, jovens e adultos para serem sujeitos ativos e críticos, viabilizando a construção de uma sociedade menos desigual, minimizando diferenças como, por exemplo, aquelas relacionadas a gênero e sexualidade. Nessa direção é que as Diretrizes Curriculares Nacionais (BRASIL, 2010) afirmam que "torna-se inadiável trazer para o debate os princípios e as práticas de um processo de inclusão social, que garanta o acesso e considere a diversidade humana, social, cultural, econômica dos grupos historicamente excluídos".

Desse modo, atentos à importância da discussão das questões de gênero e sexualidade desde a primeira infância, partimos da compreensão de que as políticas públicas e as curriculares têm um papel importante no que diz respeito ao processo de formação de professores(as) que tenham como meta a igualdade de gênero e a extinção de práticas 
sexistas. Enquanto pesquisadores envolvidos com o campo da Educação Infantil e da formação de professores(as) para atuar em tal etapa educacional, temos percebido que no currículo praticado nas escolas que atendem crianças de zero a cinco anos de idade, normalmente age-se como se gênero e sexualidade não existissem. Em relação à sexualidade infantil, observamos que a mesma é negada, em virtude de uma concepção de criança inocente, construída e propagada desde a Modernidade, que ainda faz parte do ideário pedagógico contemporâneo. Com isso queremos dizer que a inocência das crianças é vista como sinônimo de ausência de sexualidade (CRUZ, 2003). Assim, para que a inocência das crianças em relação aos desejos perdure o maior tempo possível, as professoras que atuam nas escolas acreditam que é necessário negar a curiosidade infantil, vigiar seus comportamentos, bem como ignorar toda e qualquer atividade ou discussão que se vincule à sexualidade. Para tanto, as professoras atuam na vigilância dos comportamentos infantis, geralmente prescrevendo modos de comportamento que consideram adequados para meninos e meninas, de acordo com o que deles(as) se espera dependendo do seu gênero.

Vianna (2008), ao analisar a produção acadêmica sobre as temáticas de gênero no âmbito das políticas públicas de educação, percebeu contradições entre as propostas de inclusão do gênero nos currículos escolares e a ausência de ações que garantissem a devida implementação das novas exigências para a prática docente nas escolas. Isso porque existe um descompasso entre o currículo prescrito e o praticado. Além disso, conforme Ball (1994), as políticas curriculares são discursos que constituem regimes de verdade nos quais existe uma luta pela imposição de significados em relação aos modos considerados adequados de educar as crianças. As políticas curriculares enquanto campo de produção de significados no qual a educação das crianças é "descrita, nomeada, falada, tipificada, produzida" (PARAÍSO, 2005, p. 69), nem sempre incide diretamente no trabalho docente. Por essa razão, Ball (1994) argumenta que as políticas curriculares devem ser discutidas tanto no seu contexto de produção, como de operacionalização no interior das escolas. Nessa direção torna-se possível afirmar que não basta que as temáticas de gênero e sexua- lidade constem em pareceres, em orientações, em legislações e/ou ordenamentos normativos; é preciso aproximar escolas, docentes e todos(as) os(as) demais sujeitos que dela participam às contribuições e às teorizações de pesquisadores(as) para que, de fato, haja a aproximação e a interlocução entre o que propõem documentos legais e as práticas pedagógicas postas efetivamente em prática nas instituições educacionais.

Em relação às proposições curriculares para Educação Infantil, não é diferente. Tanto o Referencial Curricular Nacional para a Educação Infantil (BRASIL, 1998) quanto as Diretrizes Curriculares Nacionais de Educação Infantil (BRASIL, 2009), mesmo que de modo pouco sistematizado, apresentam proposições a respeito das questões de gênero e sexualidade. Isso porque, como afirma Tadeu (2003), toda política curricular quer alguma coisa ou quer modificar alguma coisa em alguém. Inspirados em tal proposição, nos interessa analisar o modo como as questões de gênero e sexualidade na primeira infância são descritas nos documentos curriculares nacionais, assim como os efeitos de tais proposições legais na prática de professoras que atuam com crianças pequenas.

Portanto, tendo em vista o desenvolvimento do trabalho analítico, organizamos o artigo em quatro seções. Na primeira seção apresentaremos os aspectos metodológicos e conceituais da investigação. Na segunda seção, uma análise das proposições curriculares no que diz respeito às questões de gênero e sexualidade na Educação Infantil. Já na terceira seção focalizaremos entrevistas com professoras que atuam com crianças pequenas a respeito do modo como elas percebem o trabalho com as questões de gênero e sexualidade na escola. Por fim, na última seção abordaremos alguns desafios para pensarmos a formação docente contemporânea, em relação a uma educação que leve em consideração a importância da luta pela igualdade de gênero e de sexualidade.

\section{Aspectos metodológicos e conceituais da pesquisa}

Para realização das análises, metodologicamente estruturamos a investigação em duas etapas. Em uma primeira etapa realizamos a análise do 
Referencial Curricular Nacional para a Educação Infantil (BRASIL, 1998), das Diretrizes Curriculares Nacionais de Educação Infantil (BRASIL, 1999, 2009) e das Diretrizes Curriculares Nacionais Gerais para Educação Básica (BRASIL, 2010), cujo propósito foi, a partir de uma leitura atenta e interessada, observar o que tais documentos curriculares abordam sobre as questões de gênero e sexualidade na Educação Infantil. Na segunda etapa, realizamos entrevistas semiestruturadas com professoras que atuam em Escolas Municipais de Educação Infantil, no intuito de verificar a forma como tais documentos vêm sendo utilizados ou não no contexto das instituições. Por outro lado, para a escrita do presente capítulo optamos por um recorte menos abrangente. Focalizaremos somente a análise do segundo volume do Referencial Curricular Nacional para a Educação Infantil (BRASIL, 1998) e as Diretrizes Curriculares Nacionais de Educação Infantil (2009). Além disso, deter-nos-emos apenas em duas entrevistas realizadas com professoras que atuam com turmas de crianças de cinco anos de idade, embora o escopo da pesquisa seja mais abrangente. ${ }^{1}$

Portanto, antes de determo-nos na análise e discussão dos dados da pesquisa, consideramos importante conceituar o que entendemos por gênero e sexualidade. De acordo com Louro (2007), gênero foi um conceito desenvolvido para contestar a naturalização das diferenças sexuais em diversos espaços de disputa, enquanto sexualidade é a forma como as pessoas expressam seus desejos e prazeres na relação com os outros indivíduos e com seu próprio corpo. $\mathrm{O}$ conceito de gênero não se restringe apenas aos papéis assumidos por homens e mulheres na sociedade, mas diz respeito às relações de poder que estão implicadas entre masculino e feminino. Nessa mesma direção, Meyer (2003, p. 15 , grifo do autor) afirma que:

[...] com o conceito de gênero pretendia-se romper a equação na qual a colagem de um determinado gênero a um sexo anatômico que lhe seria 'natural-

$1 \mathrm{O}$ projeto de pesquisa do qual se origina este artigo foi aprovado pelo Comitê de Ética da Universidade à qual se vincula, bem como submetido na Plataforma Brasil (que se caracteriza por ser um sistema eletrônico criado e implantado, desde setembro de 2011, pelo Governo Federal, para sistematizar o recebimento dos projetos de pesquisa que envolvem seres humanos nos Comitês de Ética em todo o país). mente' correspondente resultava em diferenças inatas e essenciais, para argumentar que diferenças e desigualdades entre mulheres e homens eram social e culturalmente construídas e não biologicamente determinadas.

A partir da proposição da referida autora podemos dizer que as desigualdades e diferenças entre homens e mulheres explicavam-se pelas características biológicas, ou seja, estavam relacionadas exclusivamente a um sexo anatômico. Tudo isso faz parte de um processo de hierarquização através de práticas e crenças de distintas sociedades, que ao longo do tempo vem classificando e separando homens e mulheres desigualmente. Em contrapartida, o uso do conceito de gênero enquanto categoria analítica possibilita a problematização de tal entendimento, a partir do argumento de que as diferenças entre homens e mulheres são produzidas culturalmente. A esse respeito Louro (2007, p. 207) enfatiza que embora

[...] a maioria das sociedades tenha estabelecido, ao longo dos séculos, a divisão masculino/feminino como uma divisão fundamental e tenha compreendido tal divisão como relacionadas ao corpo, não se segue daí, necessariamente, a conclusão de que identidades de gênero e sexuais sejam tomadas da mesma forma em qualquer cultura.

Apesar de ao longo dos tempos a sociedade ter considerado que as diferenças entre homens e mulheres davam-se fundamentalmente em função das diferenças corporais, as diversas culturas foram transformando tanto essa ideia como a relação masculino/feminino de acordo com suas práticas sociais, políticas e principalmente através das crenças religiosas predominantes em cada lugar. Em alguns países a figura do homem ainda é colocada em primeiro plano, enquanto a mulher existe apenas para satisfazer os prazeres do parceiro e cuidar dos filhos. Em outras regiões do mundo as mulheres vêm ocupando espaços que antes eram predominantemente masculinos no mercado de trabalho e nas relações familiares.

A partir dessas considerações é possível afirmar que as diferenças entre homens e mulheres não são apenas determinadas pela biologia, mas são construções culturais e sociais. Nesse sentido, Louro (2008, p. 17) afirma que: 
Há mais de cinquenta anos, Simone de Beauvoir sacudiu a poeira dos meios intelectuais com a frase 'Ninguém nasce mulher: torna-se mulher'. A expressão causou impacto e ganhou o mundo. Mulheres das mais diferentes posições, militantes e estudiosas passaram a repeti-la para indicar que seu modo de ser e de estar no mundo não resultava de um ato único, inaugural, mas que, em vez disso, constituía-se numa construção. Fazer-se mulher dependia das marcas, dos gestos, dos comportamentos, das preferências e dos desgostos que lhes eram ensinados e reiterados, cotidianamente, conforme normas e valores de uma dada cultura.

Ou seja, os modos de se comportar, as condutas e os papéis assumidos pelos sujeitos são produzidos pela sociedade e pela cultura. Homens e mulheres aprendem a ser femininos ou masculinos em diferentes espaços: na escola, na família e na mídia, por exemplo. É “através das mais diversas instituições e práticas sociais que ao longo da vida nos constituímos como homens e mulheres, num processo que não é linear, progressivo ou harmônico" (MEYER, 2003, p. 16). Desde o momento que os pais ficam sabendo o sexo anatômico do bebê durante a gestação, já se inicia um massivo investimento para conduzir a criança para um padrão de masculinidade ou de feminilidade considerados normais pela sociedade. E a escola, mais adiante, também assume esse papel ao ensinar as crianças como serem homens e/ou mulheres. Muitos professores assumem esse discurso demarcando as diferenças entre meninos e meninas em suas práticas pedagógicas. É possível perceber a demarcação dessas diferenças quando, por exemplo, professores ensinam, mostram, definem e reiteram quais brinquedos devem ser utilizados por meninos e/ou por meninas.

Com relação à sexualidade, a partir de Weeks (2007, p. 40) é possível dizer que ela é uma "invenção histórica, a qual tem base nas possibilidades do corpo: o sentido e o peso que nós lhe atribuímos são, entretanto, modelados em situações mais concretas". Desse modo, cabe mencionar que na escola a sexualidade é vista como algo natural, que faz parte da essência do ser humano, definida quando ele nasce homem ou mulher e está predestinado a relacionar-se com alguém do sexo oposto. Como já afirmado, a sexualidade se expressa através do nosso corpo e da relação com nossas imaginações, desejos, fantasias, símbolos e padrões culturais. $\mathrm{Ou}$ seja, ela se desenvolve ao longo de nossa vida de acordo com as relações que estabelecemos com as outras pessoas e com o nosso próprio corpo; a sexualidade é provisória e está sempre em construção. E o sexo de nascimento não determina a orientação sexual de cada sujeito, pois o mesmo poderá sentir atração por pessoas do mesmo sexo ou do sexo oposto. A escola, ao reiterar a relação heterossexual como a única orientação saudável de se viver a sexualidade, torna as outras formas de vivê-la anormais. Em consequência disso, os alunos que não se encaixam nesse padrão de normalidade acabam sofrendo em razão de atos discriminatórios e preconceituosos dos quais são alvo.

Alguns autores conceituam essa questão da reiteração da heterossexualidade vista como a única possibilidade de viver a sexualidade de forma "normal" de heteronormatividade (BUTLER, 2005; LOURO, 2009). Convém referir que esse conceito de heteronormatividade, cunhado no início da década de 1990 por Michael Warner, busca referir-se ao sistema binário de caracterização sexual baseado nas genitálias. A partir daí predeterminam-se comportamentos esperados para o masculino e para o feminino (baseando-se em uma heterossexualidade compulsória). Sendo assim, heteronormatividade é um conceito que se atrela fortemente à heterossexualidade como padrão de sexualidade. Além do que é um conceito a partir do qual se procuram regular os modos de desejar, de experimentar, de viver as identidades de gênero e sexuais. Pelo fato de vivermos em uma sociedade heteronormativa, sujeitos cujas orientações sexuais são diferentes da heterossexual são marginalizados, ignorados ou perseguidos por práticas sociais, crenças ou políticas, porque - de certo modo - desestabilizam, desacomodam, chocam. Isto faz com que haja um entendimento fortemente propagado de que os sujeitos podem incluir-se exclusivamente em duas categorias distintas e complementares: masculino e feminino. Entretanto, a partir da perspectiva adotada neste artigo, entre essas duas categorias pode haver infinitas possibilidades de se viver tanto as identidades de gênero como as sexuais. 


\section{Gênero e sexualidade nas Políticas Curriculares de Educação Infantil}

O Referencial Curricular Nacional para a Educação Infantil (RCNEI), elaborado em 1998, integrou a série de Parâmetros Curriculares Nacionais elaborados pelo Ministério da Educação. Dirigido às instituições e aos profissionais de creches e pré-escolas, pode ser entendido como um conjunto de referências que tem como intuito contribuir com a implantação ou implementação "de práticas educativas de qualidade que possam promover e ampliar as condições necessárias para o exercício da cidadania das crianças brasileiras" (BRASIL, 1998, p. 13). Conforme afirma Amorim (2010), o documento foi apresentado como um guia de orientações que tinha como propósito auxiliar na elaboração dos projetos educativos das instituições. O RCNEI foi publicado em três volumes, organizados do seguinte modo: o primeiro volume é o documento "Introdução", o segundo é o documento "Formação pessoal e social", e o terceiro é o volume "Conhecimento de mundo". Interessa-nos especialmente o segundo volume, no qual é apresentado o âmbito de formação pessoal e social. Esse âmbito refere-se às experiências vivenciadas pelas crianças no contexto educacional e apresenta como eixo de trabalho o desenvolvimento da identidade e da autonomia das crianças. No que se refere às nossas questões de interesse analítico, localizamos duas seções específicas no segundo volume do referencial: a primeira intitulada "Expressão da sexualidade" e a segunda, "Identidade de gênero".

Vianna e Unbehaum (2006) afirmam em suas análises que o RCNEI defende a importância da igualdade e do respeito entre pessoas, sem distinção de gênero ou de sexualidade. Conforme as referidas autoras, o documento apresenta uma grande contribuição ao ressaltar que a construção das identidades de gênero e da própria sexualidade extrapola a configuração biológica dos seres humanos, defendendo que as crianças brinquem com as possibilidades relacionadas tanto aos papéis masculinos quanto aos femininos, para além da reprodução de estereótipos de gênero. Além disso, o documento destaca que a expressão da sexualidade relacionada ao prazer é de suma importância para o desenvolvimento psíquico infantil, abordando alguns exemplos dirigidos aos/ às docentes. Nesse sentido, consideramos oportuno apresentar alguns excertos do documento que ratificam as colocações das autoras, como poderá ser acompanhado a seguir:

No que concerne a identidade de gênero, a atitude básica é transmitir, por meio de ações e encaminhamentos, valores de igualdade e respeito entre as pessoas de sexos diferentes e permitir que a criança brinque com as possibilidades relacionadas tanto ao papel de homem como ao da mulher. Isso exige uma atenção constante por parte do professor, para que não sejam reproduzidos, nas relações com as crianças, padrões estereotipados quanto aos papéis do homem e da mulher, como, por exemplo, que à mulher cabe cuidar da casa e dos filhos e que ao homem cabe o sustento da família e a tomada de decisões, ou que homem não chora e que mulher não briga. (BRASIL, 1998, p. 41- 42).

A sexualidade tem grande importância no desenvolvimento e na vida psíquica das pessoas, pois independentemente da potencialidade reprodutiva, relaciona-se com o prazer, necessidade fundamental dos seres humanos. Nesse sentido, é entendida como algo inerente, que está presente desde o momento do nascimento, manifestando-se de formas distintas segundo as fases da vida. Seu desenvolvimento é fortemente marcado pela cultura e pela história, dado que cada sociedade cria regras que constituem parâmetros fundamentais para o comportamento sexual dos indivíduos. A marca da cultura faz-se presente desde cedo no desenvolvimento da sexualidade infantil, por exemplo, na maneira como os adultos reagem aos primeiros movimentos exploratórios que as crianças fazem em seu corpo. (BRASIL, 1998, p. 17).

Sem dúvida alguma, concordamos com Vianna e Unbehaum (2006) quando apontam que o RCNEI apresenta um importante avanço enquanto política curricular para Educação Infantil, ao chamar atenção para o caráter social e cultural do gênero e da sexualidade a partir da problematização do determinismo biológico. Para aprofundar essa discussão, lançamos mão das contribuições de Butler (2003), estudiosa que tem operado com o entendimento de que os sujeitos, desde a mais tenra idade, vão sendo produzidos como efeito dos discursos e das normas que circulam as sociedades em que estão inseridos. De acordo com essa autora, os sujeitos reiteram as normas, cultural e historicamente constituídas, que não foram dadas a priori por um(a) "criador(a)", 
mas que produzem como efeito um sujeito de um determinado gênero. Sendo assim, reiteramos a ideia de que as masculinidades e as feminilidades não surgem espontaneamente em (ou de) um corpo, não têm uma origem biológica.

Como afirmamos, é fato que tem havido um incremento e um avanço no que diz respeito às discussões sobre as questões de gênero e de sexualidade. Por outro lado, porém, questionamos o fato das questões de gênero e sexualidade serem tratadas apenas em duas seções específicas do RCNEI, como se tais discussões estivessem alijadas dos demais aspectos que dizem respeito ao desenvolvimento das crianças. Por que as questões de gênero e sexualidade não são também abordadas no terceiro volume do referencial? Gênero e sexualidade não dizem respeito ao conhecimento de mundo? De que mundo trata o referencial? Além disso, também destacamos que para além das definições sobre gênero e sexualidade ilustradas no documento, são restritas às orientações que se referem a ação pedagógica no contexto do trabalho cotidiano com as crianças nas escolas.

Diante dessa lógica de análise, consideramos importante apresentar o que diz a segunda versão das Diretrizes Curriculares Nacionais de Educação Infantil (BRASIL, 2009), cujo propósito é orientar a elaboração das propostas pedagógicas das instituições de Educação Infantil em nosso país. As DCNEI apresentam a concepção de currículo, de criança e de Educação Infantil que norteiam o documento. Conforme Amorim (2010), isso não ocorreu com as DCNEI de 1999, que orientavam a elaboração de propostas curriculares de Educação Infantil, mas não apresentavam as concepções que embasavam sua elaboração (BRASIL, 1999). As diretrizes evidenciam que as crianças enquanto sujeitos de direitos devem estar no centro do processo educativo. Para tanto, defendem uma concepção de currículo que considera o contexto da prática e a articulação das experiências e dos saberes das crianças com os conhecimentos socialmente produzidos.

O que nos chama atenção é o fato de gênero ser citado no documento apenas uma vez. Especificamente, gênero é citado no quinto aspecto da Concepção de Proposta Pedagógica, onde consta que a mesma deve possibilitar a construção de
[...] novas formas de sociabilidade e de subjetividade comprometidas com a ludicidade, a democracia, a sustentabilidade do planeta e com o rompimento de relações de dominação etária, socioeconômica, étnico racial, de gênero, regional, linguística e religiosa. (BRASIL, 2009).

Consideramos que as DCNEI (BRASIL, 2009) se eximem de uma importante função social no que diz respeito às discussões das temáticas de gênero e sexualidade no âmbito da escola. ${ }^{2}$ Desse modo, a partir da problematização apresentada a respeito da presença das questões de gênero e sexualidade nas políticas curriculares de Educação Infantil, consideramos conveniente evidenciar o modo como tais proposições têm sido entendidas por professoras no contexto da atividade docente em instituições públicas de ensino que atendem crianças de zero a cinco anos de idade.

\section{Episódios que as professoras contam: gênero e sexualidade no contexto escolar}

“O currículo está centralmente envolvido naquilo que somos, naquilo que nos tornamos, naquilo que nos tornaremos. O currículo produz, o currículo nos produz" (SILVA, 2002, p. 27).

Nas entrevistas as professoras afirmaram reiteradamente que enfrentam uma série de problemas em relação às questões de gênero e de sexualidade no cotidiano da escola, pois não sabem como devem agir com as crianças em situações que envolvem tais temáticas. Conforme os relatos das docentes, as crianças na Educação Infantil passam por uma fase de descobertas dos próprios corpos e, além disso, ficam curiosas para conhecerem os

2 Embora não seja pauta das discussões propostas no âmbito deste artigo, julgamos importante mencionar que, mesmo com a crescente visibilidade que as questões de gênero e sexualidade têm ganhado especialmente a partir do final do século XX no âmbito educacional, em 2014 tivemos a aprovação do atual Plano Nacional de Educação (PNE/ Lei 13.005/2014). Nesse Plano as questões de gênero e sexualidade sequer foram citadas e limitou-se a um objetivo genérico de combate a qualquer forma de discriminação. Em razão da não inclusão das questões de gênero e sexualidade no PNE, sugeriu-se que tais questões deveriam integrar os Planos Estaduais e Municipais de Educação, cujas apresentações e homologações deveriam ocorrer em junho de 2015. Muitos desses Planos, em suas versões iniciais, incluíram temáticas de gênero e sexualidade em seus textos, porém, quando submetidos à aprovação nas casas legislativas, acabaram sendo excluídas (GUIZZO; FELIPE, 2015). 
corpos de seus colegas. Desse modo, a solução encontrada pelas professoras para sanar as dúvidas das crianças é o planejamento de propostas envolvendo imagens, livros e filmes para mostrar as diferenças anatômicas entre os corpos masculino e o feminino. Com essa colocação, é possível observar que o trabalho referente às questões de gênero e sexualidade nas Escolas de Educação Infantil ainda é pautado exclusivamente pelo viés biológico, o que acaba limitando as possibilidades de reflexão e questionamento acerca do que pensamos sobre o corpo e sobre o que vivenciamos através dele.

Como lembra Cruz (2003, p. 106), "a sexualidade infantil, no contexto escolar, é tratada sob a ótica do problema". Fato evidenciado nos episódios narrados pelas professoras, conforme poderá ser observado na sequência.

Ando muito preocupada com o comportamento do Felipe.3 Ele apresenta um comportamento totalmente feminino. Não é apenas um detalhe. Ele sempre usa as fantasias das meninas, maquiagens e adora fazer penteados. Adora as músicas da Valeska Popuzuda. Ele sempre traz CD de funk para aula. É terrível. Quando ele ouve uma música de funk dança até o chão. Rebola sem parar. É uma tristeza. O pior de tudo é que a mãe dele nem se preocupa. Já chamei a mãe várias vezes na escola, mas não acontece nada. Ela ouve toda a situação e não fala nada. No outro dia ele retorna do mesmo jeito. Eu acho que é influencia de um irmão dele que é gay. Todas as crianças das outras turmas ficam olhando o Felipe. Quando eu faço a fila, sempre as minhas colegas ficam cochichando, apontando e me falando sobre o Felipe. É óbvio que eu vejo, mas o que eu posso fazer? Nem a coordenadora nem a diretora sabem o que fazer. Não temos nenhuma formação para lidar com esse tipo de criança. Na faculdade nunca nenhuma professora falou nada a respeito de meninos que têm comportamento de meninas. (EPISÓDIO 1 - PROFESSORA DE EDUCAÇÃO INFANTIL - TURMA DE CRIANÇAS DE 05 ANOS).

Na semana passada vivenciei uma situação constrangedora. Fiquei sem saber o que fazer. As crianças pediram para ir ao banheiro e eu deixei. Não sou uma professora autoritária, que define os horários que as crianças devem ir ao banheiro. Eles pedem e eu deixo ir, mas agora terei que mudar a minha postura. Fui chamada por uma monitora apavorada, pois uma menina e um menino da minha turma

3 Por uma questão ética, os nomes aqui citados são fictícios. estavam baixando a roupa no banheiro. Fui direto ao banheiro ver o que estava acontecendo. Quando cheguei no banheiro, percebi que eles estavam bem silenciosos, se observando. No momento, a única coisa que pensei foi em dizer para eles colocarem a roupa. Disse que a gente só tira a roupa quando esta fazendo xixi ou cocô. Fiquei muito nervosa, pois fico preocupada com a reação dos pais. Quando cheguei de volta na sala de aula, o assunto já havia se espalhado pela escola inteira. A monitora fez a fofoca e ninguém mais falava em outro assunto. Fiz uma roda com toda a turma e perguntei: 'Tem alguém aqui sem roupa?' Eles responderam: 'Não!' Então eu disse: 'Pois é. Todos nós temos que usar roupas. Ninguém deve andar pelado pela escola'. Esse fato acabou com a minha tarde. Percebi que as crianças ficaram caladas até o final da tarde. No mesmo dia mandei bilhete para as famílias e, posteriormente, conversei. O pai da menina ficou muito preocupado. Tentei explicar que era coisa de criança, mas não consegui convencer. Eu também não gostaria que isso ocorresse com minha filha. Mas o que fazer? Isso é algo que nunca se discute na escola. (EPISÓDIO 2 - PROFESSORA DE EDUCAÇÃO INFANTIL TURMA DE CRIANÇAS DE 04 ANOS).

Em ambos os episódios é possível perceber que questões do cotidiano infantil assumem a magnitude de um problema a ser resolvido pelas professoras. Problema para o qual as docentes dizem não ter formação adequada para resolver. Isso porque, mesmo com os esforços realizados pelas professoras na Escola de Educação Infantil, a sexualidade de meninos e meninas não consegue ser mantida fora da escola. Talvez, como afirma Louro (1998, p. 40), "uma das mentiras mais antigas e recorrentes da escola é a de que as crianças nada sabem sobre sexualidade".

No primeiro episódio existe uma evidente preocupação de caráter homofóbico da professora, com a possibilidade de Felipe vir a ser gay. Esquece-se completamente que o menino tem cinco anos de idade e que em tal faixa etária o jogo simbólico e as brincadeiras de faz de conta (em que a crianças assumem diferentes papeis sociais) fazem parte de sua vida enquanto criança. Caso o menino tivesse escolhido imitar um cantor de rock, de pagode ou sertanejo em sua brincadeira, ele não seria discriminado. A questão é que Felipe escolheu ser a funkeira Valeska Poposuda e isso foge ao controle 
que a professora e os demais integrantes da equipe escolar pensam ter sobre o seu corpo. Além disso, outra questão importante a ser destacada é a busca pelo histórico familiar do menino. A identificação de um irmão gay na família, de certo modo, corrobora com os investimentos que a escola realiza na busca da normalização do menino, pois existe o receio de que Felipe se torne igual a seu irmão. De fato, como afirma Louro (1998), a escola está empenhada em garantir que seus meninos e meninas se tornem homens e mulheres verdadeiros, $\mathrm{o}$ que significa dizer homens e mulheres que correspondem às formas hegemônicas de masculinidade e feminilidade. Na situação descrita, percebe-se a heteronormatividade sendo posta em circulação. Entretanto, como já afirmamos, nossas identidades não são dadas, de antemão, por determinismos biológicos. Ao contrário, masculinidades, feminilidades e sexualidades são produzidas nos sujeitos e em seus corpos, por atos aprendidos, repetidos e treinados, como efeito de normas e de discursos proferidos por instituições como a igreja, a família, a escola, a mídia, entre outras. É importante salientar que, desde as lentes teóricas que adotamos, não há identidades inatas e originais, as identidades de gênero e de sexualidade são um eterno fazer e não se resumem ao binarismo "masculino-feminino".

Outra consideração a ser feita sobre o primeiro episódio é a postura de outras professoras ao avistarem Felipe no momento de formação de filas. Enquanto professores(as) e educadores(as), é muito provável que nossas atitudes e nossas opiniões produzam efeitos sobre nossos alunos e alunas, ou seja, eles(as) aprendem não só a partir dos conteúdos curriculares com os quais trabalhamos, mas também a partir dos posicionamentos que tomamos. Então, mesmo que não intencionalmente, várias situações com as quais nos envolvemos e as quais colocamos em prática ensinam e dizem sobre gênero, sexualidade, diferença e educação.

Nessa mesma direção, Álvarez-Uría e Varela (2009) afirmam que a escola não produz as desigualdades (sejam elas de raça, classe social ou de gênero, por exemplo), mas - muitas vezes legitima-as na medida em que reitera no seu interior normas postas em circulação na sociedade. Essa reiteração se dá a partir dos comportamentos e falas de todos(as) aqueles(as) que por ela circulam, ou seja, professores, gestores, funcionários, alunos, responsáveis, entre outros.

Sendo assim, a forma como as professoras posicionaram-se diante do modo de ser de Felipe (debochando, rindo, apontando e, de certa forma, ridicularizando-o) acaba contribuindo para a legitimação de representações e discursos tomados como verdadeiros e únicos no que diz respeito aos modos de viver identidades de gênero e sexualidade. Mais do que isso, posicionamentos como os delas contribuem negativamente na formação não só de Felipe, mas também dos demais alunos e alunas, já que, em vez de minimizar, colocam em circulação determinadas formas de preconceitos e de discriminações dentro das escolas e contribuem para o desrespeito às diferenças. Diferenças que aqui não são compreendidas como marcas naturais dos sujeitos, mas como produto e efeito de certas maneiras de representá-las, ou seja, elas são decorrentes da linguagem cuja capacidade de classificar, ordenar e distinguir favorece o estabelecimento de quem são os sujeitos "desejáveis" e "normais" (BONIN; RIPOLL; GUIZZO, 2016).

No segundo episódio, a preocupação da professora é com a descoberta dos corpos que um menino e uma menina realizam no banheiro da escola. Ter visto o casal de crianças de quatro anos de idade sem roupa no banheiro torna-se o estopim para uma série de medidas de segurança a serem tomadas pela docente. A primeira medida é a de orientar as crianças, a segunda é a de restringir a saída para o banheiro e a terceira é a de informar as famílias do problema ocorrido. A visualização das crianças no banheiro assume conotação sexual, independentemente da idade delas. Isso porque crianças que se comportam dando vazão a sua sexualidade tornam-se um contraponto em relação ao discurso da criança inocente e pura (LOURO, 2007). Corroborando o argumento, Finco (2010, p. 174) afirma que "romper com modelos hegemônicos, medos e preconceitos presentes na educação de meninos e meninas não é uma tarefa fácil”. Isso porque, conforme a autora, a Educação Infantil possui a forte influência de uma formação docente para o magistério tradicional, no qual o foco são praticas fundamentadas em binômios como forte/ fraco, masculino/feminino, mente/corpo, lento/ esperto etc. 


\section{Desafios para pensar a formação docente: notas para concluir}

Para finalizar, ressaltamos que na medida em que a escola ainda é uma das mais importantes instâncias implicadas na produção das diferenças e no combate às desigualdades, torna-se imprescindível que as temáticas de gênero e sexualidade sejam abordadas no contexto da formação inicial e continuada de professores(as). Isso porque, ao direcionarmos o olhar para as escolas que atendem crianças de zero a cinco anos de idade, percebemos, assim como Cruz (2003), que tais instituições têm reforçado através de suas regras, comportamentos e discursos docentes a desigualdade entre meninos e meninas.

Dessa forma, é necessário que as políticas curriculares para Educação Infantil potencializem discussões a serem desenvolvidas no interior das escolas e dos cursos de formação docente. Além disso, também consideramos imprescindível que sejam criados programas de formação continuada de professores(as) de Educação Infantil, nos quais as temáticas de gênero e sexualidade sejam a tônica central das discussões. Justificamos tal argumento no fato constatado por Vianna e Silva (2008), de que o currículo da maioria das instituições de ensino superior de nosso país destinadas à formação docente não contemplam discussões referentes aos temas de gênero e sexualidade. No entanto, essa tarefa não é fácil, pois problematizar os discursos sexistas presentes nas escolas leva tempo e demanda um esforço conjunto, pois não basta apenas que as temáticas sobre gênero e sexualidade constem nos currículos de formação docente, é preciso aproximar as escolas e todos(as) os(as) que dela participam das contribuições e das teorizações de pesquisadores(as) para que, de fato, haja uma interlocução entre as discussões contemporâneas que problematizam as pedagogias da sexualidade e as referidas instituições.

Sendo assim, concordamos com Finco (2010, p. 161) quando afirma que discutir as relações de gênero e sexualidade na formação de professores(as) de Educação Infantil significa considerar o espaço da escola que atende crianças de zero a cinco anos de idade "como lugar de confronto e convívio com as diferenças", pois pedagogias de gênero e sexualidade perpassam todas as práticas educativas e sociais. Tais pedagogias, conforme Louro $(1998,2007)$ e Weeks (2007), estão relacionadas ao disciplinamento dos corpos, aos processos de regulamentação dos comportamentos e aos investimentos discursivos cada vez mais potentes que acompanham tais processos. Subverter a educação sexista ainda presente nas Escolas de Educação Infantil é o desafio que propomos aos/às docentes.

\section{REFERÊNCIAS}

ÁLVAREZ-URÍA, Fernando; VARELA, Julia. Sociología de las instituciones: bases sociales y culturales de la conducta. Madrid: Ediciones Morata, 2009.

AMORIM, Ana Luisa Nogueira. Sobre educar na creche: é possível pensar um currículo para crianças de zero a três anos? 2010. 338f. Tese (Doutorado em Educação) - Faculdade de Educação, Universidade Federal da Paraíba, João Pessoa, 2010.

BALL, Stephen J. Education Reform: a critical and post-estructural approach. Great Britain: Open University, 1994.

BONIN, Iara; RIPOLL, Daniela; GUIZZO, Bianca S. Para pensar a educação e as diferenças sob um enfoque cultural. Em Aberto, v. 29, n. 95, jan./jun. 2016. No prelo.

BRASIL. Ministério de Educação e do Desporto. Referencial Curricular Nacional para a Educação Infantil. Brasília, DF, 1998.

. Conselho Nacional de Educação. Resolução CEB n 01/1999. Diretrizes Curriculares Nacionais para a Educação Infantil. Brasília, DF: 1999.

Conselho Nacional de Educação. Resolução CNE/CEB n ${ }^{0}$ 05/2009. Diretrizes Curriculares Nacionais para a Educação Infantil. Brasília, DF, 2009.

. Conselho Nacional de Educação. Parecer CNE/CEB nº 07/2010, aprovado em 7 de abril de 2010. Diretrizes 
Curriculares Nacionais Gerais para a Educação Básica. Brasília, DF, 2010.

BUTLER, Judith. Problemas de gênero: feminismo e subversão da identidade. Rio de Janeiro: Civilização Brasileira, 2003.

Cuerpos que importán: sobre los limites materiales y discursivos del sexo. Buenos Aires: Paidós, 2005.

CRUZ, Elizabeth Franco. Educação sexual e educação infantil nos relatos de profissionais que trabalham com a formação de educadores de creche/pré-escola. Pro-Posições, Campinas, SP, v. 14, p. 113-117, 2003.

FINCO, Daniela. Educação Infantil, espaço de confronto e convívio com as diferenças: análise das interações entre professoras e meninas e meninos que transgridem as fronteiras de gênero. 2010. 198f. Tese (Doutorado em Educação) - Faculdade de Educação, Universidade de São Paulo, São Paulo, 2010.

GUIZZO, Bianca Salazar; FELIPE, Jane. Avanços e retrocessos em políticas públicas contemporâneas relacionadas a gênero e sexualidade: entrelaces com a Educação. In: REUNIÃO NACIONAL DA ANPEd, 37., 2015, Florianópolis. Anais eletrônicos... Florianópolis: UFSC, 2015. Disponível em: $<$ http://37reuniao.anped.org.br/wp-content/ uploads/2015/02/Trabalho-GT23-3858.pdf>. Acesso em: 29 fev. 2016.

LOURO, Guacira Lopes. Segredos e mentiras no currículo: sexualidade e gênero nas práticas escolares. In: SILVA, L. H. (Org.). A escola cidadã no contexto da globalização. Petrópolis, RJ: Vozes, 1998. p. 33-57.

Gênero, sexualidade e educação: das afinidades políticas às tensões teórico- metodológicas. Educação em Revista, Belo Horizonte, n. 46, p. 201-218, dez. 2007.

Gênero e sexualidade: pedagogias contemporâneas. Pro-Posições, v. 19, n. 2, p. 17-23, maio/ago. 2008.

Heteronormatividade e homofobia. In: JUNQUEIRA, R. D. (Org.). Diversidade sexual na educação: problematizações sobre homofobia nas escolas. Brasília: Ministério da Educação/UNESCO, 2009. v. 32, p. 85-94.

MEYER, Dagmar. Gênero e Educação: teoria e política. In: LOURO, Guacira; GOELNER, Silvana; NECKEL, Jane Felipe (Org.). Corpo, gênero e sexualidade: um debate contemporâneo na educação. Petrópolis, RJ: Vozes, 2003. p. 9-27.

PARAÍSO, Marlucy Alves. Currículo-mapa: linhas e traçados das pesquisas pós-críticas

sobre currículo. Educação e Realidade, Porto Alegre, v. 30, n. 1, p. 67-82, 2005.

SCOTT, Joan. O enigma da igualdade. Revista Estudos Feministas, Florianópolis, v. 216, n. 13, p. 11-30, jan./ abr. 2005.

SILVA, Tomaz Tadeu. Documentos de identidade: uma introdução às teorias de currículo. Belo Horizonte: Autêntica, 2002.

TADEU, Tomaz. Manifesto por um pensamento da diferença em educação. In: TADEU, Tomaz; CORAZZA, Sandra. Composições. Belo Horizonte: Autêntica, 2003. p. 9-17.

VIANNA, Cláudia Pereira. Gênero e políticas públicas de educação no Brasil: entre contradições e desafios. In: ENCONTRO DA REDE BRASILEIRA DE ESTUDOS FEMINISTAS - REDEFEM, 6., 2008, Belo Horizonte. Anais... Belo Horizonte: UFMG, 2008.

VIANNA, Cláudia Pereira; UNBEHAUM, Sandra. O gênero nas políticas públicas de educação no Brasil: 19882002. Cadernos de Pesquisa, São Paulo, v. 34, n. 121, p. 77-104, jan./abr. 2004.

Gênero na educação básica: quem se importa? Uma análise de documentos de políticas públicas no Brasil.

Educação e Sociedade, v. 28, p. 231-258, maio/ago. 2006.

VIANNA, Cláudia Pereira; SILVA, Cláudio Roberto. Contribuições para a análise da Educação Escolar. Revista Educação, São Paulo, v. 2, p. 06-15, mar. 2008.

WEEKS, Jeffrey. O corpo e a sexualidade. In: O corpo educado: pedagogias da sexualidade. In: LOURO, Guacira Lopes (Org.). 2. ed. Belo Horizonte: Autêntica, 2007. p. 35-82. 